\title{
From the coalface: does glargine insulin improve hypoglycaemic episodes, glycaemic control or affect body mass in type 1 diabetic subjects who are attending a 'routine' diabetes clinic?
}

\author{
L. A. Distiller • B. I. Joffe
}

Received: 10 August 2006 / Accepted: 15 August 2006 / Published online: 19 September 2006

(C) Springer-Verlag 2006

To the Editor: The introduction of insulin analogues with improved pharmacokinetic properties has been hailed as a major therapeutic advance for patients with type 1 and type 2 diabetes. Analogues include rapid-acting preparations, as well as those with an extended duration of action, of which a di-arginyl insulin preparation, insulin glargine, was the prototype [1]. Advantages claimed for this long-acting analogue include once daily injections, lower risk of nocturnal hypoglycaemia compared with NPH insulin injected at bedtime [2], improved glycaemic control [3] and possibly less weight gain when compared with the long-term use of NPH insulin in patients with type 2 diabetes [4]. However, these reported benefits emanated from carefully controlled clinical trials and it has therefore been repeatedly asked whether these findings can be reproduced in normal clinical practice.

The objectives of this investigation, therefore, were to determine whether type 1 diabetic patients being treated at a routine outpatient diabetes clinic would indeed demonstrate less hypoglycaemia, improved glycaemic control and less weight gain over a period of 1 year after switching from $\mathrm{NPH}$ insulin to insulin glargine.

To this purpose we assessed a random selection of type 1 diabetic patients who attended the Centre for Diabetes and Endocrinology in Johannesburg on a regular basis between January 2003 and April 2006. All subjects gave written, informed consent for use of their clinical data, and the study was carried out in accordance with the Declaration of Helsinki as revised in 2000 .

\footnotetext{
L. A. Distiller $(\square) \cdot$ B. I. Joffe

Centre for Diabetes and Endocrinology,

81 Central Street,

2198 Houghton, Johannesburg, South Africa

e-mail: larry@cdecentr.co.za
}

In total there were 121 subjects ( 75 men, 46 women) with a mean $( \pm \mathrm{SD})$ age of $39( \pm 15)$ years and a mean $( \pm \mathrm{SD})$ duration of diabetes of $19( \pm 12.5)$ years. Before switching to glargine insulin, all subjects were on a basal-bolus multiple injection regimen comprising either lispro or aspart short-acting analogue before meals and NPH insulin. NPH treatment was as follows: 82 subjects were injecting once at night, 36 twice daily, while 3 subjects were injecting NPH 3 times a day. The primary reason for changing to glargine insulin was frequent hypoglycaemic episodes (57 patients) or suboptimal glycaemic control (64 patients). In 41 patients both indications were present, but depending on the clinical situation, they were placed in one of the two above groups (hypoglycaemic episodes, suboptimal glycaemic control) as appropriate. The transfer from NPH to glargine was effected by one of the clinic's diabetes nurse educators and was made at a similar total dose to the previous regimen, with glargine being administered as a single bedtime injection. The doses of both the glargine and the rapid-acting analogue were then titrated with the help of the diabetes nurse educators over the ensuing months in an attempt to improve or maintain $\mathrm{HbA}_{1 \mathrm{c}}$ at below 7\% without inducing hypoglycaemia.

Baseline characteristics and the findings after 1 year of glargine therapy for all 121 subjects are summarised in Table 1. After 1 year on glargine insulin, no significant differences were documented with respect to change in body mass, total daily short-acting or long-acting (glargine) insulin dosages or $\mathrm{HbA}_{1 \mathrm{c}}$ concentrations. Moreover, similar findings were observed in both subgroups of patients. At the 1 year follow-up visit, the frequency of severe hypoglycaemia had decreased by $84 \%$ in the group of patients started on glargine for hypoglycaemia and by $60 \%$ for the group who had started on glargine to improve glycaemic control. 
Table 1 Clinical and biochemical characteristics of patients with type 1 diabetes mellitus just before and 1 year after changing from NPH to glargine insulin

\begin{tabular}{|c|c|c|c|c|c|c|}
\hline \multirow[t]{2}{*}{ Characteristics } & \multicolumn{2}{|c|}{ Total group $(n=121)$} & \multicolumn{2}{|c|}{ Frequent hypoglycaemia $(n=57)$} & \multicolumn{2}{|c|}{ Suboptimal control $(n=64)$} \\
\hline & $\mathrm{NPH}$ & Glargine & $\mathrm{NPH}$ & Glargine & $\mathrm{NPH}$ & Glargine \\
\hline Body mass (kg) & $74.2 \pm 12.8$ & $74.9 \pm 12.9$ & $75.4 \pm 13.1$ & $76.1 \pm 12.7$ & $73.0 \pm 12.4$ & $73.8 \pm 13.0$ \\
\hline Short-acting insulin dose $\mathrm{e}^{\mathrm{a}}$ & $30 \pm 14$ & $30 \pm 13$ & $30 \pm 13$ & $30 \pm 13$ & $30 \pm 14$ & $31 \pm 13$ \\
\hline Basal insulin dose $\mathrm{e}^{\mathrm{a}}$ & $29 \pm 13$ & $27 \pm 11$ & $28 \pm 12$ & $27 \pm 11$ & $29 \pm 13$ & $28 \pm 12$ \\
\hline $\mathrm{HbA}_{1 \mathrm{c}}(\%)$ & $8.11 \pm 1.11$ & $7.98 \pm 1.25$ & $7.30 \pm 0.73$ & $7.33 \pm 0.72$ & $8.62 \pm 1.01$ & $8.55 \pm 1.32$ \\
\hline
\end{tabular}

Values are mean $\pm \mathrm{SD}$

${ }^{\text {a }}$ Total daily dosage in units

None of the values shown above are statistically significant with $p>0.05$ in all cases using paired $t$-test comparisons

When asked to rate their preference for either NPH or glargine insulin on a scale of -5 to +5 , where -5 meant 'much prefer NPH', 0 meant 'no difference' and +5 meant 'much prefer glargine', all of the patients who had changed to glargine primarily for recurrent hypoglycaemia much preferred this insulin (rated +4 or +5 ) due to the dramatic reduction in hypoglycaemic events. Of those who were started on glargine to counter suboptimal glycaemic control, $8(12.5 \%)$ indicated that they much preferred $\mathrm{NPH}$ and asked to be switched back, $29(45.3 \%)$ indicated that it had made no real difference (rated -3 to +3 ), and only $27(42 \%)$ much preferred glargine.

In this straightforward prospective clinical audit, we found no significant correlations between individual changes in body mass and changes in $\mathrm{HbA}_{1 \mathrm{c}}$ concentrations. However, a significant positive correlation did emerge $(p<0.03)$ between changes in individual body mass and the individual basal insulin glargine dose. There was no evidence that improved glycaemic control was achieved by transferring patients from NPH to glargine insulin, irrespective of the reason for transfer; only a lessening in the number of hypoglycaemic episodes was noted. This observation is in agreement with a similar previous study $[5,6]$, although in that investigation the mean $\mathrm{HbA}_{1 \mathrm{c}}$ concentration was also significantly lowered. Reasons for this discrepancy may relate to the longer duration of followup ( 1 year versus 6 months), larger patient numbers, and a lower starting mean $\mathrm{HbA}_{1 \mathrm{c}}$ concentration in the present report.

Our study has certain limitations that should be borne in mind when interpreting the findings. Firstly, we did not assess whether glycaemic excursions [7] were in fact lower when patients changed from NPH to glargine insulin, but since the $\mathrm{HbA}_{1 \mathrm{c}}$ concentrations remained unchanged in the face of reduced hypoglycaemia, this may well be the case. Secondly, we also did not assess whether self-assessment quality of life questionnaire scores had improved.

The failure of glargine insulin to improve glycaemic control in those patients who were started on this insulin for that indication suggests that ongoing suboptimal glycaemic control is a patient problem and not an insulin problem and poor control should be addressed by patient education, support and dietary review, rather than a change to basal analogue insulin. This audit suggests that for this particular indication the use of glargine insulin is not cost-effective and any potential advantages are not appreciated by a number of the patients. On the other hand, patients with relatively satisfactory glycaemic control who are prone to regular hypoglycaemic episodes, and those with hypoglycaemia unawareness, are strong candidates for the use of glargine insulin.

Duality of interest Neither of the authors have any commercial or financial connection with any of the companies involved in the production or marketing of any insulin products or analogues. This audit did not receive sponsorship or funding from any pharmaceutical company.

\section{References}

1. Owens DR, Zinman B, Bolli GB (2001) Insulin today and beyond. Lancet 358:739-746

2. Mohn A, Strang S, Wernicke-Panteu K, Lang AM, Edge JA, Dunger B (2002) Nocturnal glucose control and free insulin levels in children with type 1 diabetes by use of the long-acting HOE 901 as part of a three-injection regimen. Diabetes Care 23:557-559

3. Pieber TR, Eugene-Jolchine I, Denobert E (2002) The European study group of HOE 901 in type 1 diabetes. Efficacy and safety of HOE 901 versus NPH insulin in patients with type 1 diabetes. Diabetes Care 23:157-162

4. Rosenstock J, Schwartz SL, Clark CM, Park GD, Danley DW, Edwards MB (2001) Basal insulin therapy in type 2 diabetes: 28week comparison of insulin glargine (HOE 901) and NPH insulin. Diabetes Care 24:631-636

5. Gallen IW, Carter C (2004) Prospective audit of the introduction of insulin glargine (Lantus) into clinical practice in type 1 diabetes. Pract Diabetes Int 21:110-114

6. Gallen IW (2005) The evolution of insulin treatment in type 1 diabetes: the advent of analogues. S Afr J Diabetes Vasc Dis 2:24-27

7. Bretzel RG (2004) Intensive insulin regimens: evidence for benefit. Int J Obes Relat Metab Disord 28(Suppl 2):S8-S13 